\title{
A Novel Model of Aggregate Gradation for Autoclaved Bricks from Tailings
}

\author{
Tingting Zhang ${ }^{1}$, Yunliang Zhao ${ }^{1, *}$, Wei Wang ${ }^{1}$, Hao Yi ${ }^{1}$, Hongqiang Li $^{2}$, Qiwu Zhang ${ }^{1, *}$ and \\ Shaoxian Song 1
}

1 School of Resources and Environmental Engineering, Wuhan University of Technology, Luoshi Road 122, Wuhan 430070, China; ajting0419@163.com (T.Z.); whutwangwei@126.com (W.W.); yihao287@126.com (H.Y.); ssx851215@whut.edu.cn (S.S.)

2 School of Resources and Environmental Engineering, Wuhan Institute of Technology, Wuhan 430205, China; lhq-18@163.com

* Correspondence: yunliang286@163.com (Y.Z.); zhangqw@whut.edu.cn (Q.Z.); Tel.: +86-27-8788-2128 (Y.Z. \& Q.Z.)

Received: 3 June 2017; Accepted: 27 June 2017; Published: 2 July 2017

\begin{abstract}
Mining tailings as a raw material for preparing autoclaved bricks have attracted much attention. The tailings subjected to milling always have the characteristic of fine granularity. However, the proportion of the fine aggregates in autoclaved bricks was very low using the current gradation formula, which impeded the utilization of the tailings. In this work, a novel model of aggregate gradation for autoclaved bricks from tailings has been presented, which was established through the following steps: (1) 91 groups of autoclaved bricks with different aggregate gradations were prepared, with the proportion of the fine aggregates $(-0.15 \mathrm{~mm})$ in the range of $40 \%$ to $100 \%$; and (2) the particle size distributions of the finest and coarsest aggregates in the high-strength region were fitted to establish the model. The proportion of the fine aggregates calculated by the model could increase significantly compared with that using the current formula. To verify the novel model, autoclaved bricks from iron ore tailings were prepared using the model, with their mechanical and freezing resistance properties meeting the requirement of the highest-strength level. It was observed by SEM that the autoclaved bricks had compact structures with a few small pores owing to the reasonable aggregate gradation.
\end{abstract}

Keywords: aggregate gradation; model; tailings; autoclaved bricks; strength

\section{Introduction}

Nowadays, massive tailings are discharged with the rapid development of the mining industry. The annual emission load of tailings in the world is more than 14 billion tons [1]. The tailings are mainly stockpiled in tailings ponds occupying large areas of land [2,3]. Moreover, there are some chemical agents and heavy metal ions remaining in tailings [4,5], which will transfer to other places and cause seriously negative impacts on the surrounding ecological environments [6,7]. Moreover, the tailing ponds used to store the tailings are potential security issues. If the ponds are broken down, it will lead to great harm to the residents [8]. Hence, it is urgent to enhance the utilization rates of tailings.

At present, the tailings are mainly used for the recovery of valuable elements $[9,10]$, the preparation of building materials [11,12], underground backfilling [13], and vegetation reclamation [14,15]. Although recovering valuable elements can realize the reduction of tailings, this has to face the problem of secondary environmental pollution owing to the secondary discharge of tailings, which is not the final way to comprehensively utilize the tailings [16]. Vegetation reclamation of tailings pond is a good way to reduce the air pollution caused by tailings, but it cannot utilize the resourceful characteristic of tailings well. 
Tailings are actually composite mineral materials, which have been processed into a fine-grain. The tailings generally have similar components to building materials [17]. The utilization of tailings in the field of construction materials has more advantages than in other areas. On the other hand, many governments have promulgated the prohibition of using clay from soil as building materials, for protecting cultivated areas [18]. Instead of clay, the autoclaved bricks from tailings have attracted much attention for their good physical performance and environmentally-friendly features $[19,20]$. Zhao et al. [21] prepared high-strength autoclaved bricks with compressive strengths of up to $21.2 \mathrm{MPa}$, using iron ore tailings. Autoclaved sand-lime bricks from copper ore tailings were prepared by Fang et al. [22], which conformed to GB11945-1999 for MU 15 autoclaved bricks [23].

The design of the aggregate gradation is a key procedure in the preparation of autoclaved bricks [24]. However, the tailings generally have the characteristic of fine granularity. Yang et al. [25] used iron ore tailings containing $96 \%$ of particles of less than $0.05 \mathrm{~mm}$ in the production of lightweight aggregates. Obinna et al. [26] reported a copper tailing with $50 \%$ of the particles less than $0.1 \mathrm{~mm}$, as an additive in cement mortars. According to the current aggregation gradation formula, the fine-grain content in autoclaved bricks is low, indicating that the tailings' proportions in autoclaved bricks will be very little; this cannot achieve the purpose of a large utilization of tailings. There is still no suitable aggregate gradation model for a high proportion of tailings in autoclaved bricks. The aggregate gradation is usually obtained through experiments, which will result in the duplication of labor. The aim of this work is to establish a new aggregate gradation model for autoclaved bricks. Through this research, the aggregate gradation of autoclaved bricks could be calculated by the new model to save the labor input. Meanwhile, the autoclaved bricks based on the model could have the characteristics of high strength and a high proportion of the fine aggregate. To verify the established model, the autoclaved bricks from iron ore tailings were prepared and characterized according to it.

\section{Materials and Methods}

\subsection{Materials}

The iron ore tailings and barren rocks, used as fine aggregates and coarse aggregates respectively, were from the Jinshandian Iron Ore Co. Ltd. of the Wuhan Iron and Steel Group in China. The barren rocks were crushed by a jaw crusher and a roll crushing mill successively. The X-ray diffraction (XRD) patterns of the tailings and crushed barren rocks are shown in Figure $1 \mathrm{a}, \mathrm{b}$, respectively. The major minerals in the iron ore tailings were quartz, calcite, chlorite and diopside. In addition, a spot of gypsum, pyrite, feldspar and mica minerals also existed. The barren rocks mainly contained quartz, feldspar and pyroxene, and a small amount of mica. Table 1 shows the chemical compositions of the tailings and barren rocks. The content of $\mathrm{SiO}_{2}$ in the iron tailings and barren rocks were $35.43 \%$ and $57.40 \%$ respectively, indicating that using the barren rocks as the coarse aggregate could increase the proportion of silica in the raw material to a certain extent. 

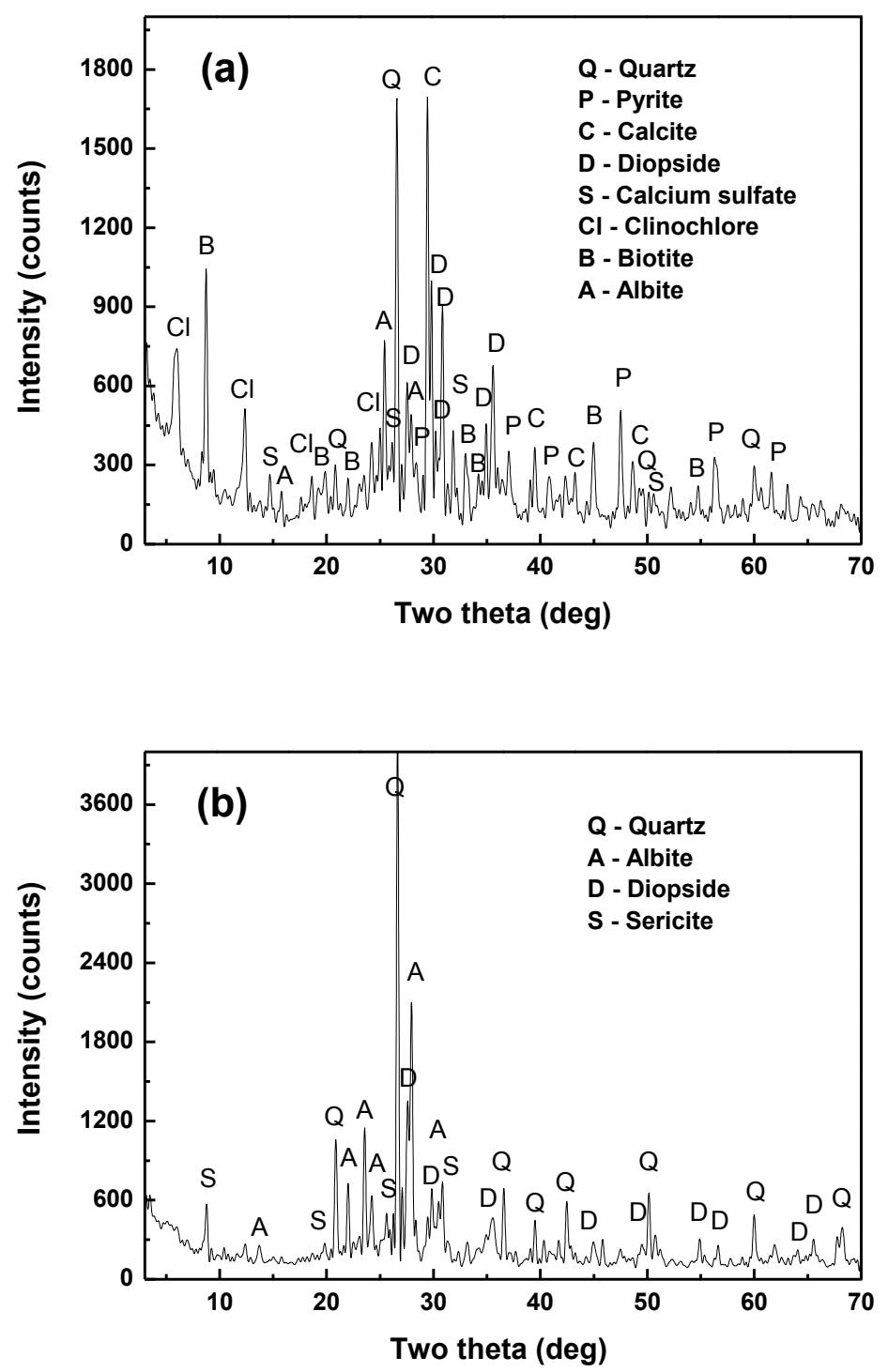

Figure 1. XRD (X-ray diffraction) patterns of (a) iron ore tailings and (b) barren rocks.

Table 1. Chemical composition of iron ore tailings and barren rocks.

\begin{tabular}{ccc}
\hline Composition (\%) & Iron Ore Tailings & Barren Rocks \\
\hline $\mathrm{Na}_{2} \mathrm{O}$ & 1.34 & 3.86 \\
$\mathrm{MgO}$ & 9.70 & 3.95 \\
$\mathrm{Al}_{2} \mathrm{O}_{3}$ & 9.41 & 13.09 \\
$\mathrm{SiO}_{2}$ & 35.43 & 57.40 \\
$\mathrm{P}_{2} \mathrm{O}_{5}$ & 0.76 & 0.27 \\
$\mathrm{~K}_{2} \mathrm{O}$ & 1.27 & 2.87 \\
$\mathrm{CaO}$ & 13.01 & 6.84 \\
$\mathrm{TiO}$ & 0.52 & 0.53 \\
$\mathrm{TFe}$ & 6.22 & 4.19 \\
$\mathrm{BaO}$ & 0.03 & 0.03 \\
$\mathrm{SO}$ & 5.98 & 1.10 \\
$\mathrm{L.O.I}$ & 13.05 & 3.41 \\
\hline
\end{tabular}


The particle-size distributions of the iron ore tailings and crushed barren rocks are provided in Figure 2. The particle size of the iron ore tailings was fine: the proportion of particles less than $74 \mu \mathrm{m}$ was about $86 \%$. For the crushed barren rocks, the proportion of particle sizes greater than $0.5 \mathrm{~mm}$ was up to $50 \%$, and the proportion greater than $1 \mathrm{~mm}$ was about $30 \%$; this meant that the crushed barren rocks were suitable as coarse aggregates. A portion of crushed rocks were sieved into several narrow-sized fractions to adjust the gradation.

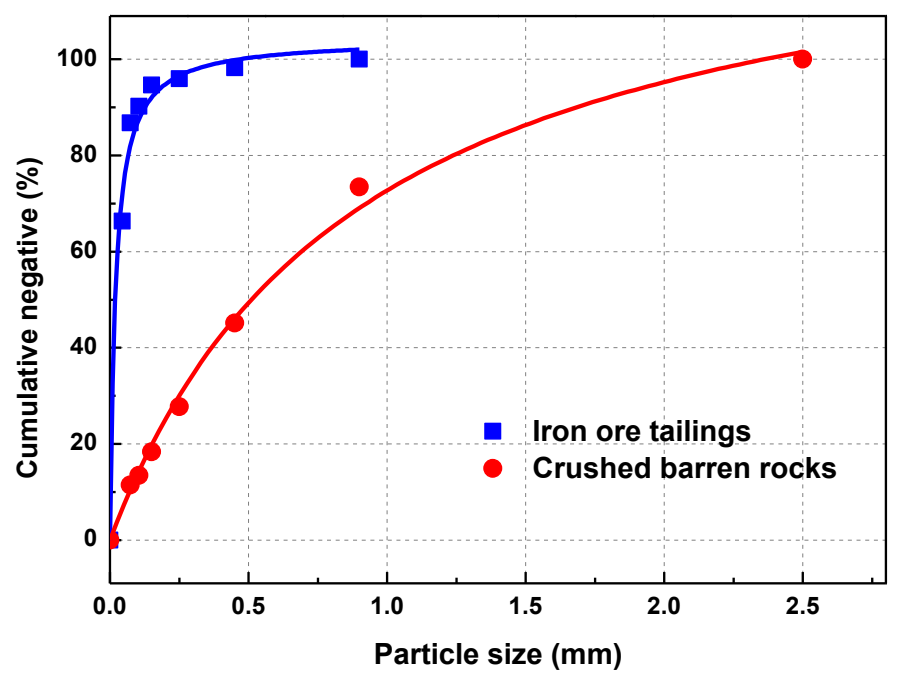

Figure 2. Particle-size distributions of iron ore tailings and crushed barren rocks.

Lime as a calcium raw material was taken from Chunshun New Building Materials Co. Ltd in the Hubei Province of China. The performance index of the lime are shown in Table 2, and met the requirement for first-grade lime, according to the Lime for Silicate Building Products Standard (JC/T 621-2009) [27].

Table 2. Performance index of the lime.

\begin{tabular}{ccccc}
\hline Item & $\begin{array}{c}\text { Particle Size over } \mathbf{0 . 0 7 4} \\
\mathbf{m m}(\mathbf{\%})\end{array}$ & $\begin{array}{c}\text { Slaking Temperature } \\
\left({ }^{\circ} \mathbf{C}\right)\end{array}$ & $\begin{array}{c}\text { Slaking Time } \\
(\mathbf{m i n})\end{array}$ & $\begin{array}{c}\text { Content of Unbound } \\
\mathbf{C a O}(\%)\end{array}$ \\
\hline Index & 8.21 & 99 & 4.7 & 88.6 \\
\hline
\end{tabular}

\subsection{Preparation Methods}

\subsubsection{Experiment Design for Establishment of the Aggregate Gradation Model}

The crushed barren rocks were sieved into three fractions, including less than $0.15,0.15$ to $1.2 \mathrm{~mm}$, and 1.2 to $2.5 \mathrm{~mm}$, which were defined as the fine fraction, intermediate fraction and coarse fraction, respectively. The ternary components of fine, intermediate and coarse fractions with different gradations were designed, in which the addition contents of fine, intermediate and coarse fractions were in the range of $40 \%$ to $100 \%, 0 \%$ to $60 \%$, and $0 \%$ to $60 \%$ with an interval of $5 \%$, respectively. The total number of the groups with different gradations was 91 , and each group had 8 specimens. The preparation parameters were set according to the previous research [21]. The preparation parameters for autoclaved bricks of the cylinder with $\Phi=50 \times 23 \mathrm{~mm}$ were a lime addition content of $12 \%$, a molding moisture of $12 \%$, a molding pressure of $20 \mathrm{MPa}$, and an autoclaved pressure and time of $1.2 \mathrm{MPa}$ and $6 \mathrm{~h}$, respectively. 


\subsubsection{Preparation of Autoclaved Bricks with Iron Ore Tailings}

A certain proportion of iron ore tailings, barren rocks and lime were weighed accurately by an electronic balance and mixed for $3 \mathrm{~min}$ by a JJ-5 mixer (Jianxing, Cangzhou, China). The mixtures were then mixed with a certain amount of water for $5 \mathrm{~min}$. After mixing, the mixtures were taken out and slaked for $2 \mathrm{~h}$, then they were put into the mixer again to mix with a certain amount of water for $3 \mathrm{~min}$. After the final mixing, the mixture was weighed to place into a stainless steel mold, and formed by a $20 \mathrm{MPa}$ press into a cuboid of $240 \mathrm{~mm} \times 115 \mathrm{~mm} \times 53 \mathrm{~mm}$. Following the adobes pre-curing for $24 \mathrm{~h}$, steam autoclaving with a certain pressure time was carried out to obtain the autoclaved bricks. Finally, the bricks were tested for compressive strength, flexural strength and freezing resistance properties.

\subsection{Measurements}

The mechanical and durability properties of the autoclaved bricks were measured according to the Test Methods of Wall Bricks Standard (GB/T 2542-2003) [28].

The particle-size distributions of the iron tailings and crushed barren rocks were measured by an XSB-88 sieve shaker (Huatong, Hebi, China).

An AXIOS advanced X-ray fluorescence analyzer (XRF, PANalytical B.V., Almelo, The Netherlands) was used to determine the chemical compositions of the raw materials.

Mineral phase analysis was conducted by a D/Max-IIIA X-ray diffractometer (XRD, Rigaku, Tokyo, Japan) with $\mathrm{Cu}-\mathrm{K} \alpha$ radiation, at a voltage of $40 \mathrm{kV}$ and a current of $30 \mathrm{~mA}$, and at the scanning rate of $15^{\circ} / \mathrm{min}$ from $3^{\circ}$ to $70^{\circ}$.

The morphologic features of the autoclaved bricks were observed using a JSM-5610LV scanning electron microscope (SEM, JEOL, Tokyo, Japan) with magnifications of $500 \times$ to $10,000 \times$.

\section{Results and Discussion}

\subsection{Establishment of the Aggregate Gradation Model}

The compressive strengths of the bricks with different aggregate gradations were determined, and were divided into three grades: 10-20 MPa for low-strength, 20-30 MPa for medium-strength, and more than $30 \mathrm{MPa}$ for high-strength. The compressive strength distribution in the ternary chart of fine, intermediate and coarse fractions is shown in Figure 3. The location of the symbol in the ternary chart represents the contents of the fine, intermediate and coarse fractions in the bricks, and the form of the symbol demonstrates the compressive strength of the bricks. It was observed that there were 12 high-strength points, in which 10 high-strength points were highly concentrated. The 10 points formed a region, which was called the high-strength region. The aggregate gradation of the high-strength bricks was in the closed region that formed by the particle-size distribution curves of the finest and coarsest fractions, whose particle-size distributions are shown in Figure 4. 


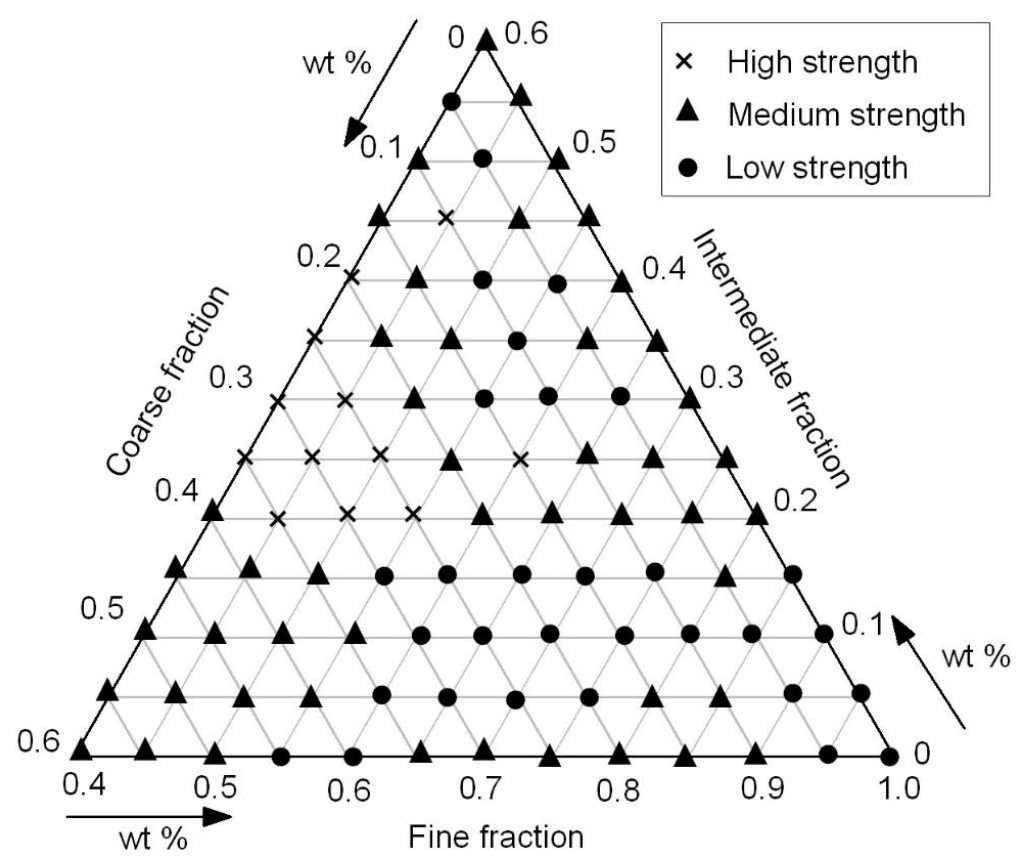

Figure 3. Compressive strength ternary chart of fine, intermediate and coarse fractions.

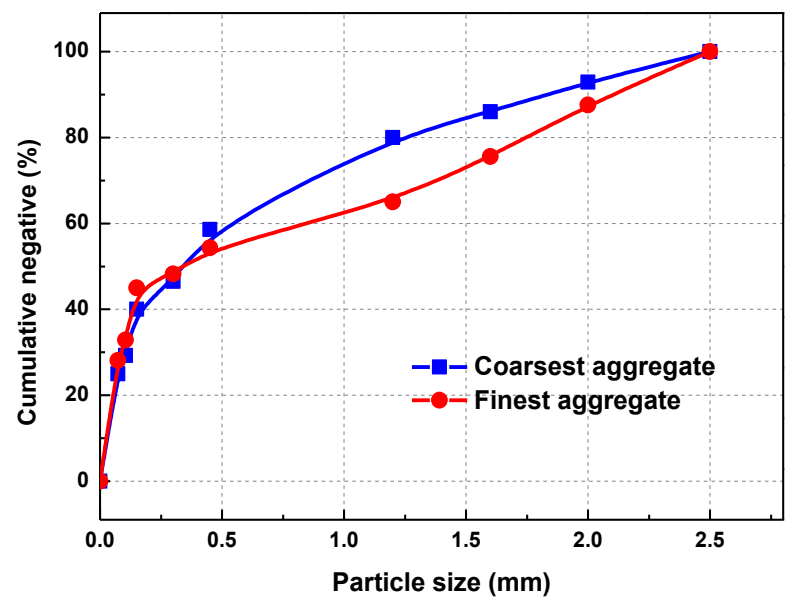

Figure 4. Particle-size distributions of the finest and coarsest aggregates in the high-strength region.

The current gradation design formula for the autoclaved bricks is as follows [29]:

$$
P_{d}=\left(d / d_{\max }\right)^{0.5}
$$

where $d$ is a certain size of the aggregate, $P_{d}$ is the negative accumulation of $d$, and $d_{\max }$ is the maximum size of the aggregate. According to Equation (1), if $d_{\max }$ is $2.5 \mathrm{~mm}$, the negative accumulation of $0.15 \mathrm{~mm}$ will be $24.49 \%$.

According to the current gradation design formula seen as Equation (1), it is known that $P_{d}$ is related to $d / d_{\text {max }}$. In this work, combining the current gradation design formula and the particle-size distribution of the aggregates in the high-strength region, $P_{d}$ as the polynomial function of $d / d_{\max }$ was constructed as is shown in Equation (2), in which $a, b$, and $K$ are the coefficients to control the proportion of the fine aggregates.

$$
P_{d}=a\left(d / d_{\max }\right)^{b}+(100-a)\left(d / d_{\max }\right)^{K}
$$


The finest aggregate in the high-strength region was fitted according to Equation (2) (Figure 5). The coefficients $a, b$, and $K$ were obtained, which were $62.25,0.22$, and 0.39 respectively, and the correlation coefficient was 0.9953 .

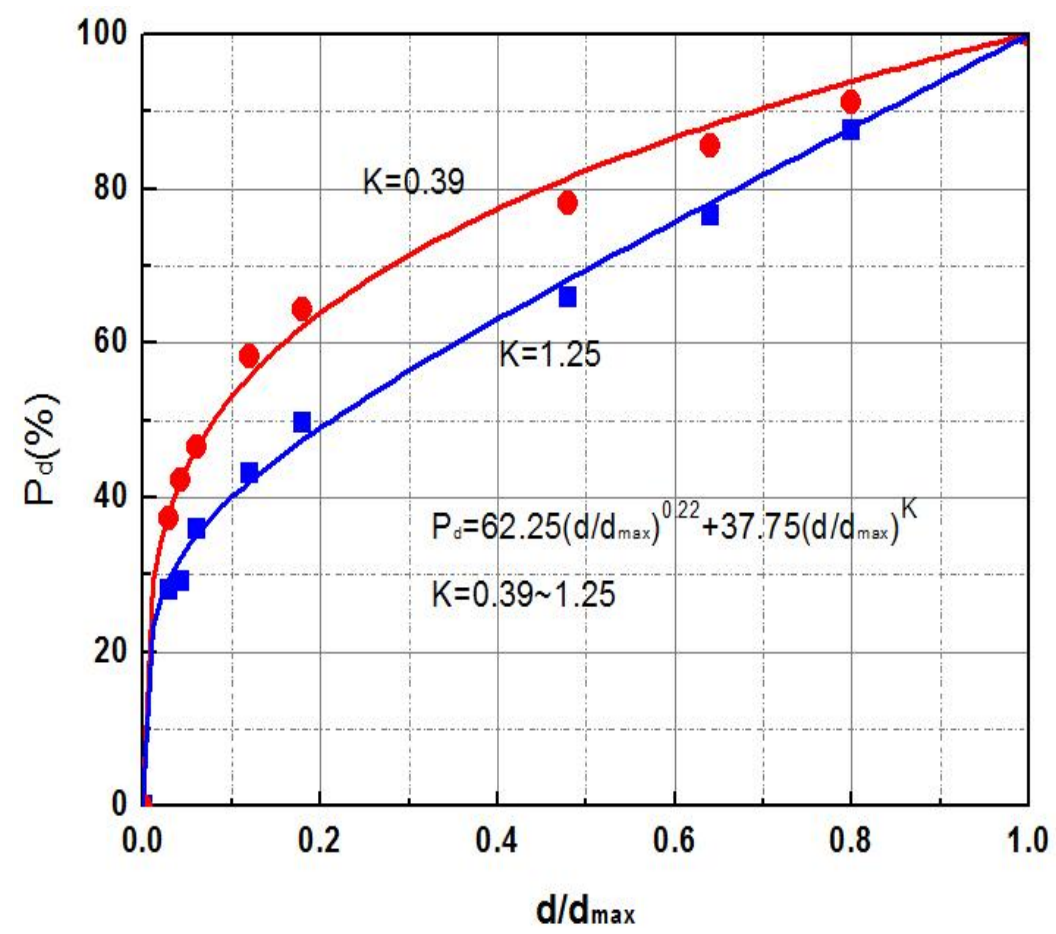

Figure 5. Fitting curves of the $P_{d}$ polynomial function of $d / d_{\max }$ for the finest and coarsest aggregates of the autoclaved bricks in the high-strength region.

Fixing $a=62.25$ and $b=0.22$, the coarsest aggregate in the high-strength region was fitted (Figure 5). The coefficient $K$ of 1.25 was obtained, and the correlation coefficient was 0.9980 .

Summarizing the above, the aggregate gradation design formula for the high-strength-tailings autoclaved bricks could be concluded as follows:

$$
P_{d}=62.25\left(d / d_{\max }\right)^{0.22}+37.75\left(d / d_{\max }\right)^{K}
$$

where $K$ was the correction index of the gradation with a range of $0.39-1.25$. According to Equation (3) the negative accumulation of $0.15 \mathrm{~mm}$ could reach $46.12 \%$ with a $d_{\max }$ of $2.5 \mathrm{~mm}$, which improves the fine-aggregate proportion significantly when compared with the $24.49 \%$ using the current aggregate gradation design formula of Equation (1). The mechanical property of the autoclaved bricks decreased gradually with an increasing of the fine-size content [24]. However, higher fine-tailings' mixing compositions have important connotations in the production of autoclaved bricks, so as to consume fine-tailings as much as possible to lower the content within slime and sand [20]. Thus, the gradation design was one of the biggest concerns, which was confirmed through experiments [30]. The newly established gradation design model may save much labor input.

3.2. Verification of the Gradation Design Model by Preparation of High-Strength Autoclaved Bricks with Iron Ore Tailings

\section{Gradation Design}

The autoclaved bricks from the iron ore tailings and barren rocks were prepared according to the newly established gradation design model, and the bricks' properties were measured to verify this model. 
According to the particle-size distributions of the iron ore tailings and crushed barren rocks in Figure 2, the particle size of $2.5 \mathrm{~mm}$ was chosen as $d_{\max }$. Meanwhile, in order to improve the fine-aggregate addition content, the minimum gradation correction index $K=0.39$ was selected. Hence, the gradation design formula was as follows:

$$
P_{d}=62.25(d / 2.5)^{0.22}+37.75(d / 2.5)^{0.39}
$$

The particle-size distribution of the aggregates of the tailings' autoclaved bricks was calculated based on Equation (4), and the results are shown in Table 3. The negative accumulation of $0.074 \mathrm{~mm}$ of the iron ore tailings and the calculated aggregates were $86.80 \%$ (Figure 2) and $38.26 \%$ (Table 3), respectively. The iron ore tailings' addition content could be calculated as $44.08 \%$. Based on this, the particle-size distribution of the adjusted aggregate was obtained, which is presented in Table 3. The particle-size distribution calculated by the new model was similar to that reported in other literature [21], where the aggregation gradation was confirmed by experiments.

Table 3. Particle-size distributions of calculated and adjusted aggregates.

\begin{tabular}{ccccccc}
\hline Size fraction $(\mathbf{m m})$ & $<0.074$ & $0.074-0.15$ & $0.15-0.45$ & $0.45-0.9$ & $0.9-1.2$ & $1.2-2.5$ \\
Calculated aggregate (\%) & 38.26 & 7.86 & 15.91 & 13.03 & 6.26 & 18.68 \\
Adjusted aggregate (\%) & 0 & 4.4 & 14.33 & 12.25 & 6.26 & 18.68 \\
\hline
\end{tabular}

\subsection{Characterization of the Autoclaved Bricks}

\subsubsection{Mechanical and Freezing Resistance Properties}

The autoclaved bricks were prepared according to the calculated aggregate gradation mentioned above (Figure 6). The mechanical and freezing resistance properties of the autoclaved bricks were tested, and the results are provided in Table 4; these were compared with the proposed values of the Chinese National Standard of Autoclaved Lime-sand Brick (GB11945-1999) for MU25 autoclaved bricks [23]. It was noted that the mechanical and freezing resistance properties of the bricks satisfied the requirements of the MU25 level in the standard. The strength level of the tailing autoclaved bricks reported by publications is always around 15-20 MPa [22,30], which is much lower than that of this work, indicating that the preparation of high-strength autoclaved bricks according to the new model is reliable.

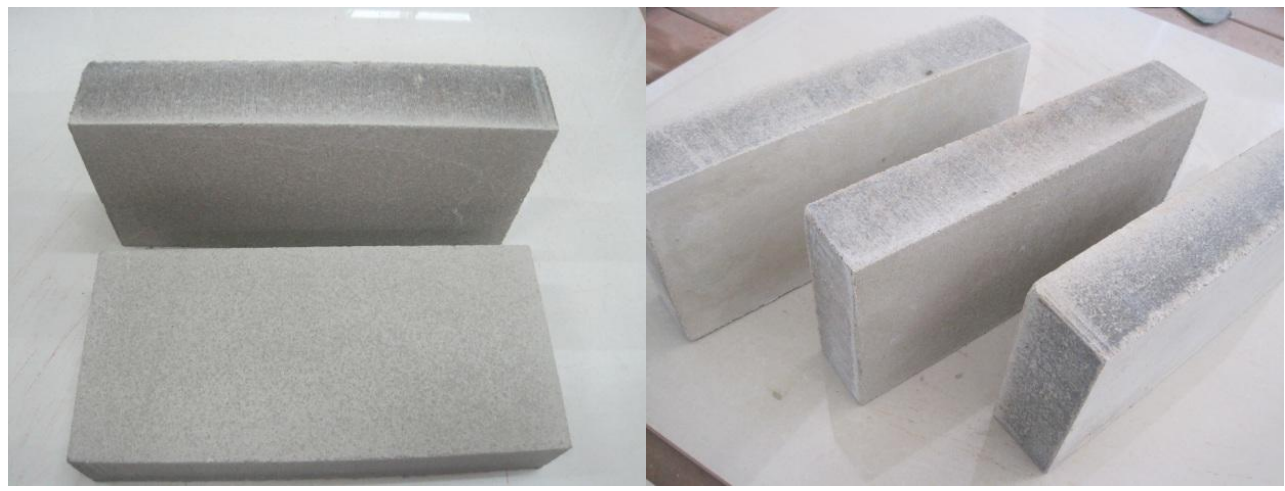

Figure 6. Photographs of autoclaved bricks according to the aggregate gradation model. 
Table 4. Mechanical and freezing resistance properties of autoclaved bricks according to the calculated aggregate gradation and optimum autoclave system.

\begin{tabular}{ccc}
\hline Item & $\begin{array}{c}\text { Measured } \\
\text { Value }\end{array}$ & $\begin{array}{c}\text { Proposed } \\
\text { Value }\end{array}$ \\
\hline Compressive strength $(\mathrm{MPa})$ & 30.14 & $\geq 25.0$ \\
Flexural strength $(\mathrm{MPa})$ & 5.98 & $\geq 5.0$ \\
Compressive strength after 15 freezing-thawing cycles $(\mathrm{MPa})$ & 26.52 & $\geq 20.0$ \\
Mass loss after 15 freezing-thawing cycles $(\%)$ & 0.74 & $\leq 2.0$ \\
\hline
\end{tabular}

\subsubsection{XRD and SEM Analysis}

Figure 7 shows the XRD pattern of the autoclaved bricks, indicating that the main phases in the bricks were quartz, calcite, feldspar, afwillite, tobermorite and xonotlite, for which the quartz, calcite, and feldspar were derived from tailings, while the afwillite, tobermorite and xonotlite were new phases generated during the autoclaved curing. It can be concluded that the $\mathrm{SiO}_{2}$ in the tailings was dissolved and reacted with $\mathrm{Ca}(\mathrm{OH})_{2}$, generating the new phases mentioned above. The generated phases, especially the afwillite and tobermorite, contributed to the increase in the strength of the brick due to the physical-mechanical properties [31].

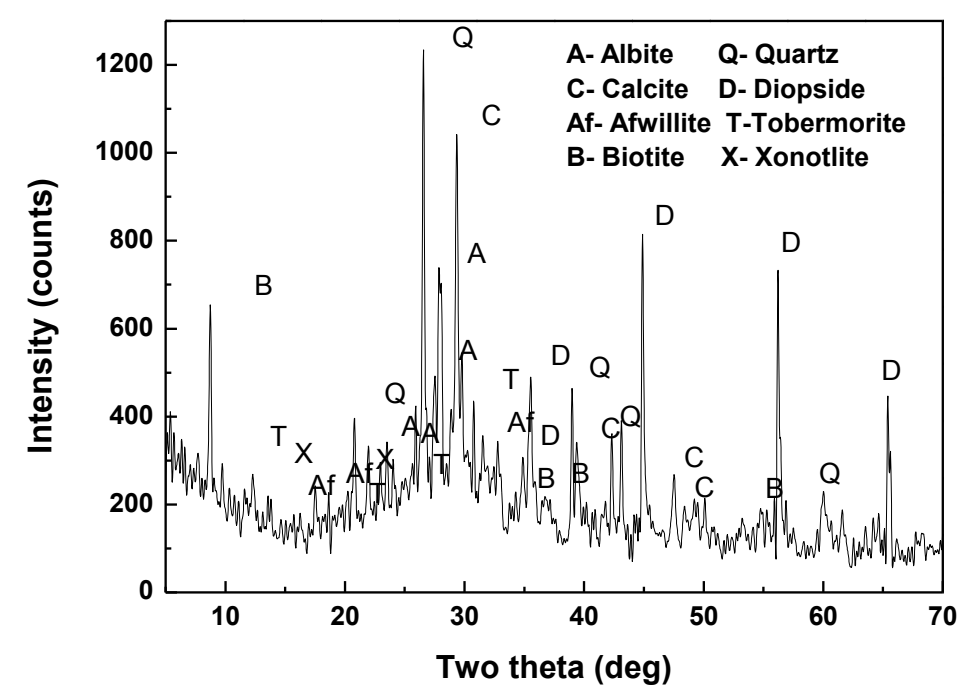

Figure 7. XRD pattern of autoclaved bricks by optimum aggregate gradation and the autoclave system.

It can be seen from Figure $8 \mathrm{a}, \mathrm{b}$ that the autoclaved bricks had a compact structure with few small pores, due to the good aggregate gradation providing the basics for the high strength. Figure $8 \mathrm{c}, \mathrm{d}$ shows that flake-like tobermorite, fibrous xonotlite, short columnar afwillite and gel were coated on the surface of tailings, and connected the particles to form a firm unit, which further increased the high strength of the autoclaved bricks with more compact structures and lower porosities. 


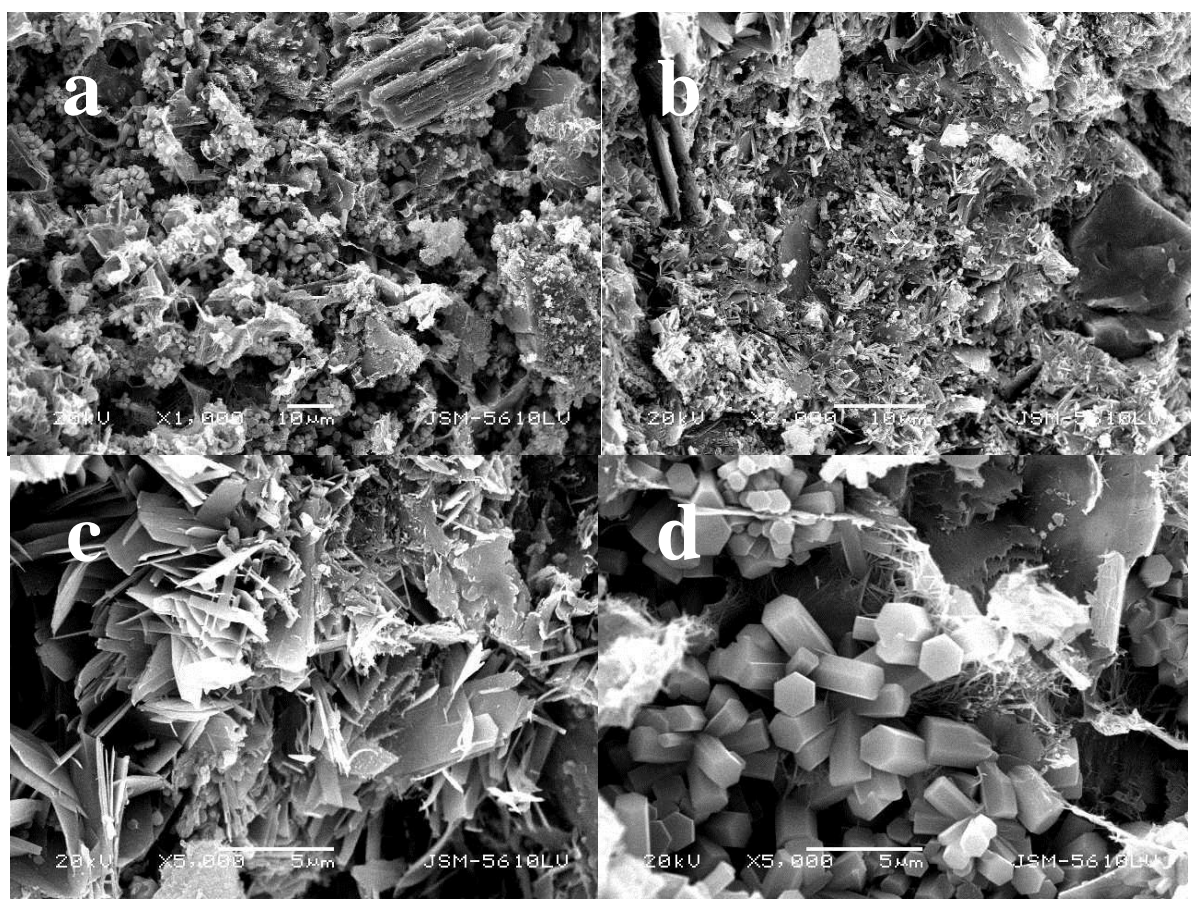

Figure 8. Scanning electron microscope (SEM) morphologies of the autoclaved bricks by calculated aggregate gradation and the optimum autoclave system.

\section{Conclusions}

In this work, a novel model of aggregate gradation for autoclaved bricks from tailings was established. The proportion of the fine aggregates calculated by the model could increase significantly, compared with that using the current formula. The established model was well verified through the autoclaved brick preparation from the iron ore tailings, whose mechanical and freezing resistance properties met the requirement of the highest-strength level. The morphology analysis indicated that the autoclaved bricks had compact structures with few small pores because of the good aggregate gradation, contributing to the high strength of the autoclaved bricks. This suggested that if the raw materials had the characteristics of a high proportion of fine fractions, such as the tailings did, the novel model could be used for the aggregate gradation of autoclaved bricks, to save the labor input.

Acknowledgments: The financial support for this work from the Natural Science Foundation of Hubei Province of China (2015CFB221, 2016CFA013) and the Wuhan Science and Technology Bureau (2016070204020156) are gratefully acknowledged.

Author Contributions: Yunliang Zhao and Qiwu Zhang conceived and designed the experiments; Tingting Zhang and Wei Wang performed the experiments; Hao Yi and Hongqiang Li analyzed the data; Qiwu Zhang and Shaoxian Song contributed reagents, materials, and analysis tools; and Tingting Zhang wrote the paper.

Conflicts of Interest: The authors declare no conflict of interest.

\section{References}

1. Jones, H.; Boger, D.V. Sustainability and Waste Management in the Resource Industries. Ind. Eng. Chem. Res. 2012, 51, 10057-10065. [CrossRef]

2. Xiao, E.; Krumins, V.; Tang, S.; Xiao, T.; Ning, Z.; Lan, X.; Sun, W. Correlating microbial community profiles with geochemical conditions in a watershed heavily contaminated by an antimony tailing pond. Environ. Pollut. 2016, 215, 141-153. [CrossRef] [PubMed]

3. Huang, X.; Deng, H.; Zheng, C.; Cao, G. Hydrogeochemical signatures and evolution of groundwater impacted by the Bayan Obo tailing pond in northwest China. Sci. Total Environ. 2016, 543, 357-372. [CrossRef] [PubMed] 
4. Schoenberger, E. Environmentally sustainable mining: The case of tailings storage facilities. Resour. Policy 2016, 49, 119-128. [CrossRef]

5. Si, W.; He, X.; Li, A.; Liu, L.; Li, J.; Gong, D.; Liu, J.; Liu, J.; Shen, W.; Zhang, X. Application of an integrated biomarker response index to assess ground water contamination in the vicinity of a rare earth mine tailings site. Environ. Sci. Pollut. Res. 2016, 23, 17345-17356. [CrossRef] [PubMed]

6. Suzuki, Y.; Takenaka, C.; Tomioka, R.; Tsubota, H.; Takasaki, Y.; Umemura, T. Accumulation of Arsenic and Copper by Bryophytes Growing in an Aquatic Environment near Copper Mine Tailings. Mine Water Environ. 2016, 35, 265-272. [CrossRef]

7. Mathuthu, M.; Kamunda, C.; Madhuku, M. Modelling of Radiological Health Risks from Gold Mine Tailings in Wonderfonteinspruit Catchment Area, South Africa. Int. J. Environ. Res. Public Health 2016, 13, 570. [CrossRef] [PubMed]

8. Rico, M.; Benito, G.; Díez-Herrero, A. Floods from tailings dam failures. J. Hazard. Mater. 2008, 154, 79-87. [CrossRef] [PubMed]

9. Lv, C.C.; Ding, J.; Qian, P.; Li, Q.C.; Ye, S.F.; Chen, Y.F. Comprehensive recovery of metals from cyanidation tailing. Miner. Eng. 2015, 70, 141-147. [CrossRef]

10. Chen, L.; Xiong, D.; Huang, H. Pulsating high-gradient magnetic separation of fine hematite from tailings. Miner. Metall. Process. 2009, 26, 163-168.

11. Cheng, Y.H.; Huang, F.; Li, W.C.; Liu, R.; Li, G.L.; Wei, J.M. Test research on the effects of mechanochemically activated iron tailings on the compressive strength of concrete. Constr. Build. Mater. 2016, 118, 164-170. [CrossRef]

12. Ahmari, S.; Zhang, L. Durability and leaching behavior of mine tailings-based geopolymer bricks. Constr. Build. Mater. 2013, 44, 743-750. [CrossRef]

13. Yilmaz, E.; Fall, M. Paste Tailings Management; Springer International Publishing: Cham, Switzerland, 2017.

14. Rojo, A.; Hansen, H.K.; Ottosen, L.M. Electrodialytic remediation of copper mine tailings: Comparing different operational conditions. Miner. Eng. 2006, 19, 500-504. [CrossRef]

15. Chaphekar, S. Reclamation of mill tailings. Curr. Sci. 2001, 81, 1278.

16. Zhang, S.; Xue, X.; Liu, X.; Duan, P.; Yang, H.; Jiang, T.; Wang, D.; Liu, R. Current situation and comprehensive utilization of iron ore tailing resources. J. Min. Sci. 2006, 42, 403-408. [CrossRef]

17. Bayat, O.; Vapur, H. Utilization of Turkish chromite tailings in the manufacturing of building bricks. Asian J. Chem. 2005, 17, 791-797.

18. Chen, Y.; Zhang, Y.; Chen, T.; Zhao, Y.; Bao, S. Preparation of eco-friendly construction bricks from hematite tailings. Constr. Build. Mater. 2011, 25, 2107-2111. [CrossRef]

19. Cicek, T.; Tanriverdi, M. Lime based steam autoclaved fly ash bricks. Constr. Build. Mater. 2007, 21, 1295-1300. [CrossRef]

20. Du, B.; Zhou, C.; Duan, N. Recycling of electrolytic manganese solid waste in autoclaved bricks preparation in China. J. Mater. Cycles Waste Manag. 2014, 16, 258-269. [CrossRef]

21. Zhao, Y.; Zhang, Y.; Chen, T.; Chen, Y.; Bao, S. Preparation of high strength autoclaved bricks from hematite tailings. Constr. Build. Mater. 2012, 28, 450-455. [CrossRef]

22. Fang, Y.; Cu, Y.; Kang, Q.; Wen, Q.; Dai, P. Utilization of copper tailing for autoclaved sand-lime brick. Constr. Build. Mater. 2011, 25, 867-872. [CrossRef]

23. Autoclaved Lime-Sand Brick; GB 11945-1999; Bureau of Quality and Technical Supervision of China: Beijing, China, 1999.

24. Zhou, C.; Du, B.; Wang, N.; Chen, Z. Preparation and strength property of autoclaved bricks from electrolytic manganese residue. J. Clean. Prod. 2014, 84, 707-714. [CrossRef]

25. Yang, C.; Cui, C.; Qin, J. Recycling of low-silicon iron tailings in the production of lightweight aggregates. Ceram. Int. 2015, 41, 1213-1221. [CrossRef]

26. Onuaguluchi, O.; Eren, Ö. Recycling of copper tailings as an additive in cement mortars. Constr. Build. Mater. 2012, 37, 723-727. [CrossRef]

27. Lime for Silicate Building Products Standard; JC/T 621-2009; Ministry of Industry and Information Technology of the People's Republic of China: Beijing, China, 2009.

28. Test Methods of Wall Bricks Standard; GB/T 2542-2003; Bureau of Quality and Technical Supervision of China: Beijing, China, 2003. 
29. Chen, Z.; Yuan, W.; Zheng, D. Study on the application of grading theory. J. Chongqing Jiaotong Univ. 2005, $24,44-48$.

30. Zhao, F.Q.; Zhao, J.; Liu, H.J. Autoclaved brick from low-silicon tailings. Constr. Build. Mater. 2009, 23, 538-541. [CrossRef]

31. Arabi, N.; Jauberthie, R.; Sellami, A. Autoclaved sand-lime bricks: Influence of addition of blast furnace slag on the formation of phases. Mater. Struct. 2013, 46, 181-190. [CrossRef] 